\title{
Does ingestion of plants from a phenetic group of Monochoria ('Diyahabarala') cause hepatotoxicity?
}

\author{
V Ileperuma ${ }^{1}$, S Udage ${ }^{1}$, D Yakandawala', L Jayasinghe ${ }^{2}$, S Kumar ${ }^{2}$, A Ratnatilleke ${ }^{3}$
}

Ceylon Medical Journal 2015; 60: 28-30

\section{Introduction}

'Diyahabarala' is a freshwater aquatic herb having an inflorescence with bright purplish blue flowers. This plant is an essential ingredient in the well known 'Neelayadithailaya' used as a hair-oil in traditional medicine. The plant is used for treating many ailments such as toothache, asthma, cough, cold, fever, stomach and liver problems, general debility, haemorrhage, hepatitis, anaemia, scurvy, dipsia, strangury, gastropathy, hepatopathy, odontalgia and diabetes [1]. It is also used externally as an antidote to snakebite poisoning, and for burns and scalds [3]. According to traditional medicine the 'diyahabarala' plant is a food which cools the body. Consumption of the plant leaves either as porridge ('kola-kenda') or salad ('mellun') is recommended [2]. Studies have endorsed the medicinal potential of $M$. vaginalis. Based on a study showing a hepato-protective effect, $M$. vaginalis has been used in the development of phytomedicines against hepatic disorders and oxidative damage $[3,4]$.

We report hepatotoxicity in a patient who ingested 'diyahabarala' porridge ('kola-kenda') as a remedy for diabetes.

\section{Case report}

A 39-year old diabetic patient was admitted with fever and vomiting for eleven days. On examination he was febrile, icteric and had tender hepatomegaly. The alanine transaminase was $>2000 \mathrm{IU} / 1$, There was bile in urine and high serum bilirubin indicating hepato-cellular damage. Screening for viral hepatitis was negative. He was managed with intravenous fluids, soluble insulin and symptomatic treatment. He improved around day 14 after admission. Direct questioning found that he had recently ingested 'diyahabarala porridge (kola-kenda)' daily, to control diabetes.

\section{Discussion}

Monochoria vaginalis is a well-known medicinal plant used in traditional and ayurvedic medicines in Sri Lanka. In Sri Lanka the plant genus Monochoria has two species, Monochoria vaginalis (Burm. f.) Presl and M. hastata (L.) Solms-Laub. Monochoria vaginalis is commoner compared to M. hastata and is frequently encountered in paddy fields. Inquiries regarding the use of the plant in local medicine from ayurvedic and traditional physicians revealed that a distinction is not made between $M$. hastata or M. vaginalis, Majority of physicians were unaware of the two different species of plants, but simply referred to both plants by the common Sinhala name 'diyahabarala'. However, studies on the morphology of the plant showed that mostly it was $M$. vaginalis, which was used for medicinal purposes. Recent studies on species limits of the genus Monochoria in Sri Lanka described the occurrence of three phenetic groups within M. vaginalis and one phenetic group possessed idioblasts in leaves which were filled with a red coloured substance that has not been recorded before [5]. This plant group can be easily separated from the others based on the rough texture of the leaves (Figure 1). Occurrence of these phenetic groups are also supported by a study which compared the biological activity of leaf extracts and also detecting the presence of phytochemicals with possible toxic effects in extracts taken from these different phenetic groups. According to the results it is evident that the phenetic group with idioblasts of $M$. vaginalis has a different chemical profile compared to the other two phenetic groups within M. vaginalis as well as M. hastata. All plant groups showed properties that could explain their medicinal value. High antioxidant activity (AOA) of the extracts is related to reducing oxidative damage initiated by free radicals which causes cell and tissue damage. AOA determined by the DPPH assay of the extracts, and was found to be significantly high [6]. Diyahabarala extracts also inhibited $\alpha$-amylase a carbohydrate hydrolyzing enzyme, which slows down glucose absorption and hence helps to reduce postprandial hyperglycaemia [7]. Therefore results suggest that extractable phytochemicals present in 'diyahabarala' display properties that contribute to the prevention of type 2 diabetes.

In addition the phenetic group with idioblasts of $M$. vaginalis showed a high brine shrimp lethality ( $\mathrm{LD}^{50}$, $40 \mathrm{mg} \mathrm{dm}^{-3}$ ) which is an indication of cytotoxicity and a high haemolysis percentage (100\% at $1000 \mathrm{ppm})$, both in boiled and un-boiled plant leaf extracts [8]. The very

${ }^{1}$ Department of Botany, Faculty of Science, University of Peradeniya, ${ }^{2}$ Institute of Fundamental Studies, Hantana Road, Kandy, ${ }^{3}$ National Hospital of Sri Lanka, Sri Lanka.

Correspondence: DY, e-mail: <deepthiyakandawala@gmail.com>. Received 15 August and revised version accepted 29 December 2014. Competing interests: none declared. 
A

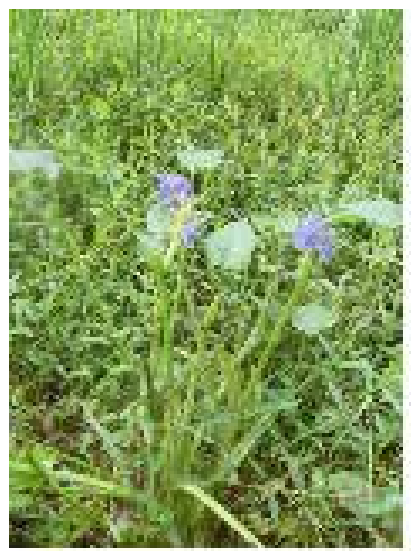

C
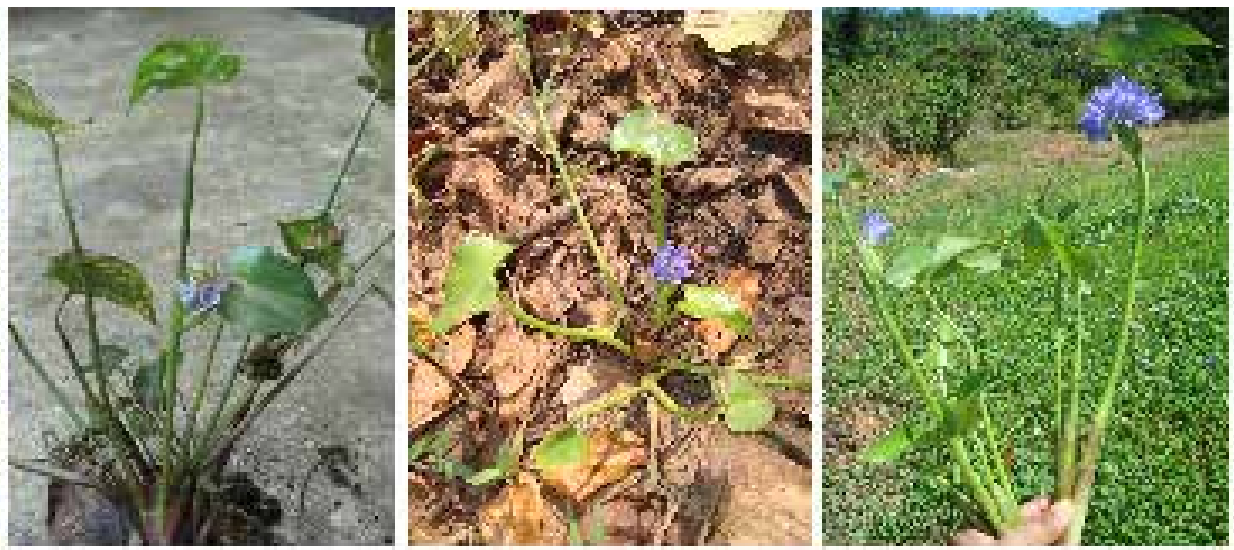

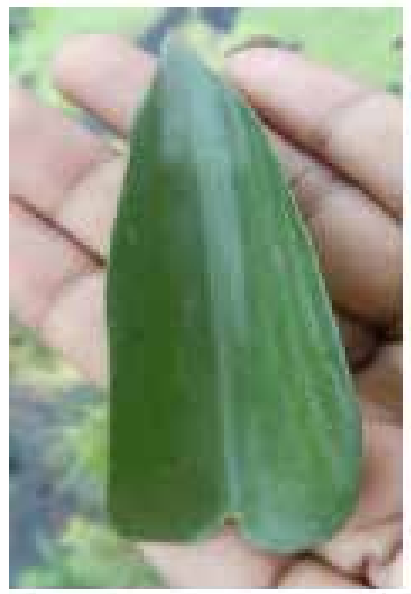

B

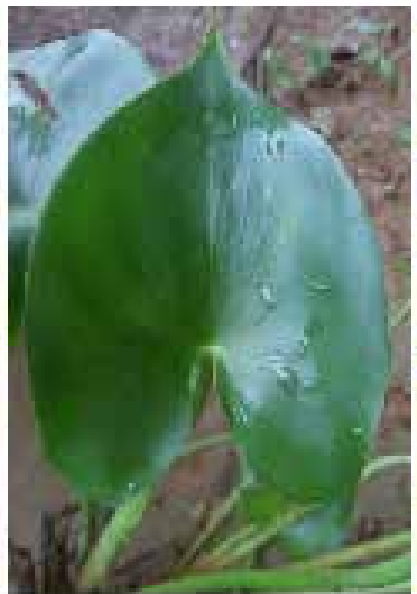

D

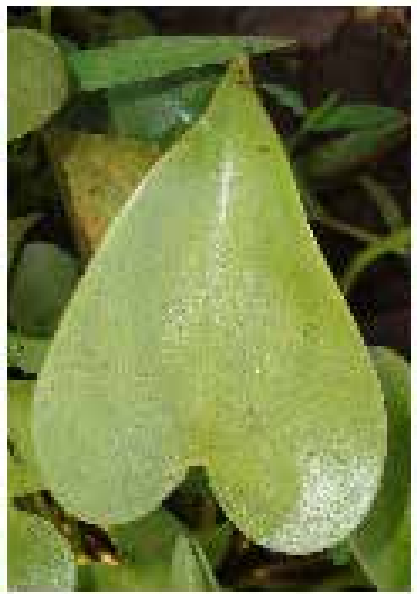

F

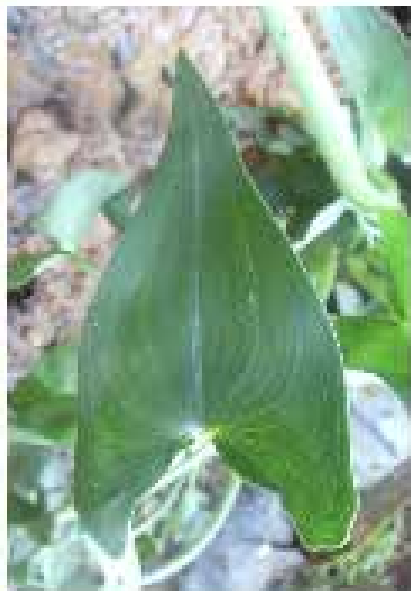

H

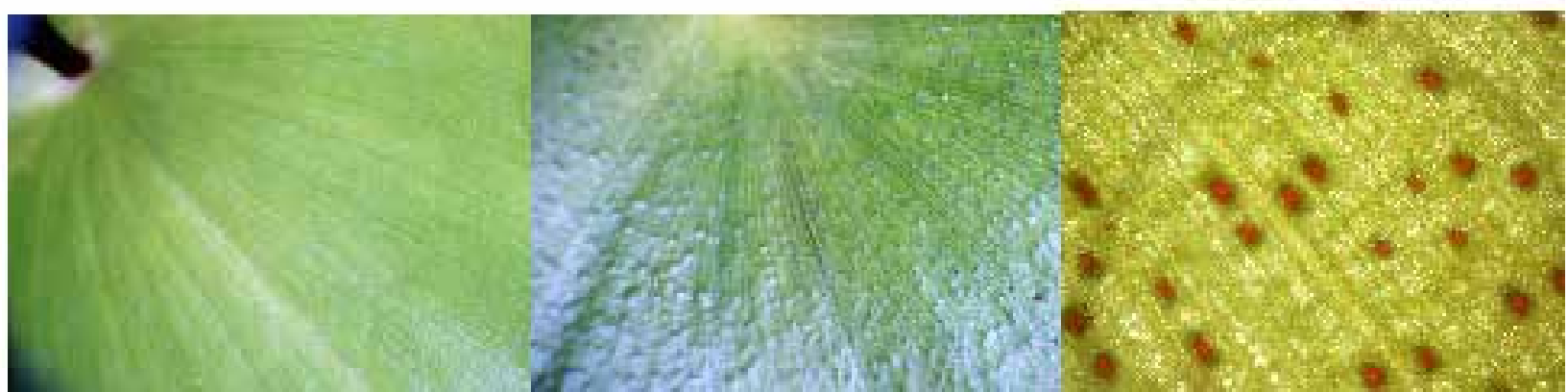

Figure 1. Habit and leaf morphology. A and $B: M$. vaginalis phenetic group $A, C$ and $\mathbf{D}: M$. vaginalis phenetic group B; E and F: $M$. vaginalis phenetic group $C$ (the group with idioblasts in the leaf surface) and $\mathbf{G}$ and $\mathrm{H}:$ M. hastata.

Leaf upper surfaces under a USB microscope. I: Leaf without idioblasts - note the smooth surface (M. hastata and Group A and B of $M$. vaginalis). J: Leaf surface of phenetic group $C$ of $M$. vaginalis - note the rough surface showing rough appearance in the places where the idioblasts are present under the epidermis. $\mathrm{K}$ : A closer look of a leaf surface of phenetic group $C$ of $M$. vaginalis under a stero-microscope - note the red colour dots. 
low $\mathrm{LD}^{50}$ values (the concentration where $50 \%$ mortality of second instar nauplii occurs) indicate high toxicity to brine shrimps and the ability to cause some allergic effects on mammals. The presence of the high haemolytic ability after boiling indicates that the substances responsible for haemolysis activity are heat stable. Haemolytic activity is an indicator of general toxicity for normal cells and could explain the observed hepatotoxicity. The results obtained from the brine shrimp lethality and haemolytic assays indicate that accumulation of toxic substance(s) after ingestion of 'Diyahabarala kola-kenda', as treatment for diabetes, which could have resulted in the clinical picture of this patient.

Even though many studies have validated the medicinal potential of $M$. vaginalis, the present study has provided evidence of occurrence of a phenotype group in $M$. vaginalis with a different chemical composition which should caution against the indiscriminate use of this plant. It should be noted that a species belonging to the same genus (Monochoria in the current study) with medicinal benefits does not necessarily mean that all species in that genus are equally effective.

In conclusion the results highlight the importance of correct identification of medicinal plants that are used in both ayurvedic and traditional medicines in order to reap their benefits.

\section{Acknowledgements}

Authors wish to thank Prof. N. K. B. Adikaram, Dr. Gehan Jayasooriya, and Mr. Piyal Karunaratne, Department of Botany and, Dr. L. J. P. Anura P. Jayasooriya, Department of Basic Veterinary Sciences, University of Peradeniya for their constructive comments.

\section{References}

1. Gupta MK, Savadi RV, Manjunath KP, et al. Pharmacognostical investigation roots of Monochoria vaginalis Presl. Anc Sci Life 2008; 28: 7-9.

2. Ali SKM, Kumara RKC. Study on factors responsible for high life expectancy in the elderly population in the peripheral area of northwest Sinharaja forest. Journal of the Ruhuna University 2013; 1: 3-8.

3. Latha B, Latha MS. Antioxidant and curative effect of Monochoria vaginalis methanolic extract against carbon tetrachloride induced acute liver injury in rats. Der Pharma Chemica 2013; 5: 306-12.

4. Chinna RR, Periyasamy M, Muthukumar A, Anand G. Antidiabetic and Hypolipidemic Activity of Monochoria vaginalis Presl. On Alloxan Induced Diabetic Rats. International Journal for Pharmaceutical Research Scholars 2013; 2: I-3.

5. Udage Savithri, Yakandawala Deepthi. Morphological variation and species boundaries of the genus Monochoria (Pontederiaceae) in Sri Lanka. Proceedings and abstracts of The Peradeniya University Research Sessions, PURSE 2011; 16: 189.

6. Tepe B, Eminagaoglu O, Akpulat HA, Aydin E. Antioxidant potentials and rosmarinic acid levels of the methanolic exracts of Salvia verticillata (L.) subsp verticillata and S. verticillata (L.) subsp. Amasiaca (Freyn \& Bornm) Bornm. Food Chemistry 100: 985-89.

7. Nickavar B, Abolhasani L, Izadpanah H. $\alpha$-Amylase Inhibitory Activities of six Salvia Species. Iran J Pharm Res 2008; 7: 297-303.

8. Michael AS, Thompson CG, Abramovitz M. Artemia salina as a test organism for a bioassay. Science 1956; 123: 464.

\section{Declaration of Interest}

There are no conflicts of interest. 